\title{
Enemigos de los Escorpiones : dos especies de aves de la America tropical (Tucanes)
}

\author{
par Luis MAZZOTTI † \\ Instituto de Salubridad - Enfermedades tropicales. Mexico
}

\begin{abstract}
Resumen
Dos especies de las aves tropicales llamadas «tucanes»: Pteroglossus torquatus erithrozonus y Ramphastos sulfuratus mostraron en experimentos de laboratorio, ser enemigas de los escorpiones.
\end{abstract}

\section{Résumé}

Deux espèces d'oiseaux d'Amérique tropicale, appelés «toucans », peuvent être considérées comme des ennemis des scorpions, d'après des observations effectuées au laboratoire. Ce sont: Pteroglossus torquatus erithrozonus et Ramphastos sulfuratus.

Millot y Vachon (1949) recopilaron varias observaciones sobre los enemigos de los alacranes como son: algunas especies de monos cercopitecos africanos, ciertos reptiles como la víbora Echis carinata y lagartijas de los géneros Varanus y Lacerta. Entre las aves, mencionaron dichos autores a las aves de corral y al ibis Comatibis eremita. Respecto a los artrópodos se refirieron a la manta religiosa, los grandes escalopendras y algunos solífugos. Berland (1949) hizo notar el papel del erizo como cazador y comedor de escorpiones en el Sahara.

Vachon (1954) observó iguales facultades en una lechuza Atene noctua capturada de Turquía. Hace referencia a Le Bret quien señaló la notable actividad de las aves

† A notre profond regret, le Pr Mazzotti est décédé au cours de la publication de ce numéro. 
africanas de rapiña Sagittarius serpentarius para alimentarse de escorpiones. Asi mismo da cuenta de las observaciones aisladas hechas por Hislop y por Adams, separadamente en la India, sobre el ataque de una libélula y una abeja a sendos escorpiones.

Alvarez del Toro (1960) ha dado a conocer la agresividad de la culebra Stenorrhina freminville de la costa de Chiapas (México) contra los escorpiones.

Mazzotti (1964) mantuvo en el laboratorio durante tres meses, una tarántula del género Aphonopelma, que fué colectada en la costa del Pacífico de México, la cual alimentó con un escorpión semanal de la especie tóxica Centrurus limpidus. Este mismo autor (1966) observó que el « coati » Nasua narica es un ávido comedor de escorpiones y parece tener inmunidad natural frente a sus picaduras. Este autor dió sucesivamente 96 ejemplares de Centrurus limpidus a un coati adulto, el cual los comió todos en menos de una hora. Al final del experimento, el animal, evidentemente saciado, mostró alguna torpeza en sus movimientos y tos ligera, recuperándose poco tiempo después.

Por otra parte, un ejemplar de Potos flavus se mostró deseoso de comer más, después de haber ingerido los tres únicos ejemplares con que contaba el laboratorio.

Este mismo autor confirmó la agresividad de las gallinas, las cuales picotean al escorpión para matarlo antes de comerlo. Desafortunadamente para aquellas, el escorpión al defenderse alcanza a picar las barbillas del ave. De ocho gallinas que fueron picadas en esa forma, murieron cuatro y las otras se recuperaron después de sufrir un cuadro de paresia.

Los patos no toman la precaución de matar al escorpión y éste los pica en las mucosas bucales y quizá en la farínge y esófago. Tres patos que ingirieron : 3, 9 y 14 escorpiones respectivamente, en el término de una hora, murieron entre una y doce horas después; otros tres patos que comieron 8, 9 y 10 escorpiones se salvaron pero sufrieron un estado cataléptico que se mantuvo algo más de 24 horas.

Dos especies de mamíferos, Procyon lotor y Didelphis marsupialis no mostraron ninguna agresividad contra los escorpiones (Mazzotti, 1966).

\section{Observaciones recientes}

Hace poco pude observar a dos ejemplares de aves de las llamadas « tucanes », originarios de la península de Yucatán, pertenecientes respectivamente a las especies Pteroglossus torquatus erithrozonus (tucán de collar) y Ramphastos sulfuratus (pito real) los cuales al encontrarse frente a ejemplares de Centrurus gracilis se comportaron ambos en forma similar. En primer lugar los atacaron con la punta de su pico hasta dejarlos muertos; en seguida los colocaron transversalmente en la parte media del pico y los despedazaron gradualmente con los bordes afilados del mismo, recogiendo los segmentos grandes que caían al suelo para continuar el seccionamiento. Una vez terminada esta operación el tucán recogió cada fragmento con la punta del pico y levantó éste casi verticalmente, abriéndolo con amplitud de modo que el fragmento cayera a la faringe para deglutirlo. 


\section{Referencias}

Alvarez del Toro (M.), 1960. - Los Reptiles de Chiapas. Tuxtla Gutierrez, Chis., Instituto Zoológico del Estado, p. 174.

Berland (L.), 1949. - Le Hérisson, ennemi des Scorpions. Enthomologiste, Paris, 5, 199 (Vachon, 1954).

Hislop (J. A.), 1946. - Dragon-fly prying on a Scorpion. J. Bombay Nat. History, 46, 557 (Vachon, 1954).

Mazzotti (L.), 1964. - Enemigos de los alacranes. Tarántula del género Aphonopelma. Rev. Inst. Salub. Enferm. trop. (Mex), 24, 9-10.

-, 1966. - Estudio sobre enemigos naturales de los alacranes. Rev. Inst. Salub. Enferm. trop. 26, 51-55.

Millot (J.), y Vachon (M.), 1949. - Scorpions. Traité de Zoologie, de P. P. Grassé, Paris. Masson, t. VI, p. 425.

Phythinan-Adams (E. G.), 1949. - Bee v. Scorpion. J. Bombay Nat. History, 48, 382 (Vachon, 1954).

VACHON (M.), 1954. - Remarques sur les ennemis des scorpions. L'oiseau et R.F.O., 24, 171-174. 